\title{
HIRED - Helping Industry Reach Engineers Directly An Initiative of Engagement - for Students and Employers
}

\author{
Carolyn Geddert P. Eng. \\ University of Manitoba \\ Carolyn_Geddert@umanitoba.ca \\ Lynda Peto \\ University of Manitoba \\ Lynda.Peto@umaniotba.ca \\ Mathew Riesmeyer \\ University of Manitoba \\ umriesme@myumanitoba.ca
}

\begin{abstract}
In an effort to connect Engineering students with the diverse engineering community in Manitoba, University of Manitoba Engineering Society (UMES) and the faculty have collaborated and organized a regular weekly meeting called HIRED an acronym for "Helping Industry Reach Engineers Directly". Industry partners are invited and eager to present to an average of 100 students in attendance on a variety of topics. It's about sharing information about companies, career opportunities, industry insights, safety in the workplace, employment and employability skills, networking, and job search success. The benefits to students and industry partners are clear. Students are gaining a better understanding of the opportunities available within their profession and learn first-hand about what employers are looking for in an engineering graduate. Employers have the opportunity to meet their future employees and share with students the importance of professional skills and how to make the most out of their engineering education. These weekly meetings are strategically scheduled every Monday night from 5:30 through the fall and winter academic terms with a meal as part of the deal. It's a winning combination for the students, employers, profession and the faculty.
\end{abstract}

Keywords: Industry, Engagement, Career

\section{INTRODUCTION}

In an effort to connect Engineering Students with the diverse engineering community in Manitoba, The University of Manitoba Engineering Society (UMES) and the Co-operative education and Industrial Internship Program (Co-op/IIP) for the faculty have collaborated and organized a regular weekly meeting.
The meeting is scheduled every Monday night at 5:30 through the fall and winter academic terms. This regularity allows students to plan their weekly schedule to accommodate attendance. The presentations are most commonly made by industry partners who wish to highlight opportunities for engineering students and graduates within their company or industry. This time has also been used to present information about the Engineering community in Manitoba generally, provided opportunities for networking or even special presentations on topics such as workplace safety, employability skills, or ethics. These topics may also align with graduate attributes.

Attendance at these events is made to be very convenient for students. The event is at 5:30 PM every Monday. This coincides with the end of most classes or labs for the day. The event always includes a meal for the students. These deliberate arrangements have resulted in an average attendance of approximately 100 students. The UMES has promoted this event to the student population as vital to their professional development and encourages all students to attend.

\section{INDUSTRY NEEDS}

\subsection{Industry conditions}

Manitoba's current unemployment rate is $5.3 \%$ is making for a tight labour market and the projections for the next 5 years indicate that the labour market will get even tighter (Province of Manitoba, 2014). While these conditions create a prime environment for graduate employment, the labour shortages are making it difficult for employers to find and attract new employees. Post-secondary institutions are a logical 
place for employers to be looking to fulfill their human resource needs and establishing a recruiting pipeline early with upcoming grads. Employers are requesting and looking for opportunities to enhance their campus presence and improve their recruiting results in order to access qualified engineer candidates (Cole, 2014). They are looking for ways to market their companies for recruitment purposes but in addition also wanting to share with students what skills and experience they value in new employees. The Canadian Manufacturers and Exporters says that "employee skills and the ability of employers to attract and retain skilled workers will be central to our economic success over the next decade." (Standing Committee on Human Resources, Skills and Social Development, 2012)

\subsection{Industry conditions that leads to lack of visibility for students}

Students engaged in career development activities including getting related work experience in their degree contributes to their successful transition into the world of work when they graduate (CBI, 2009). The opportunity to build and strengthen relationships with employers including small local companies is beneficial for both students and employers while students are in their academic program. Often students are not aware of employers until they start engaging in career development (CBI, 2009). Students and new grads can learn about work opportunities and learn first-hand about the skills and experience that are valued in their workplace. Students are often familiar with large companies because of their profile in our community but these companies traditionally experience slower growth with little increase in new jobs (Education Advisory Board, 2013). Small and medium size business are creating the majority of job creation across the country (Royal Bank of Canada, 2014). These firms are often overlooked because they lack brand awareness among students. Through HIRED, students become more connected to a diverse group of employers that can offer opportunities throughout their entire career path. One of Manitoba's largest manufacturing employers has seen a dramatically different response rate to their job postings since they have become involved in HIRED events. Deb Tabor, Human Resources Manager from MacDon Industries states, "the opportunity to get in front of students so they can learn what we do and understand what opportunities we have for their future careers has made a dramatic difference to our responses on job postings. We are getting a great pool of candidates responding now" (Tabor, 2015).

\subsubsection{Olds Paradigms Do Not Work}

Most worker in the $21^{\text {st }}$ century will have 15 different jobs and change careers at least 3 times (Workopolis Research, 2014). This is much different than previous generations where workers were sometimes employed their whole working life with the same company. Changes in the workforce are transforming recruitment strategies and changing how companies think about their workers. A tight labour supply, aging workers, and changing career goals for Generation X, Y and Zoomers are changing the human resources landscape. Job security, work/life balance, flexible work options, meaningful work and advancement opportunity are all important to new hires (Civian, 2007). Employers are needing to understand and respond to these changes in order to keep talent and maintain knowledge capital in today's competitive environment. Students and new grads are evaluating job opportunities based on this criteria. Employers are needing to find ways to make connections and no longer are traditional career fairs or informal information sessions offering value with reaching a large target audience with respect to quality of the contact, time and cost (Education Advisory Board, 2013). Employers are using HIRED to communicate these benefits to assist in their recruitment targets offering high value for their time and money.

\section{ENGAGING STUDENTS REQUIRES CONSISTANT EFFORT}

Getting the attention of busy and often stressed students can often be challenging. The UMES and Coop/IIP at the University of Manitoba have collaborated to identify ways to overcome these challenges. Students are often not motivated to participate in activities that occur outside of academic classes, even activities they recognize as important. Some of this distraction is due to fatigue, the burden of coping with self-care (getting enough to eat or getting enough rest), and pressure to excel in their studies. The HIRED events include some specific logistical plans to help reduce the distraction and offer a relief to some of these pressures.

\subsection{Response To Student Needs}

When the University of Manitoba Engineering Society (UMES) and the Engineering Co-op Office first started planning the logistics of the HIRED Night Monday's, the two groups put a great focus on the needs of the students. In order to implement a successful service for students, being very conscious of 
their needs was critical. For example if HIRED was scheduled at a time that did not work with students' schedule, no matter the benefit, they would not be able to take advantage of that service. There were three major factors that contributed to the initial success of HIRED: (1) arrangements were made so that no midterms were held on Mondays, (2) food was provided for all students that attend, and (3) the UMES made sure the students knew about the upcoming HIRED event(s). These three factors naturally allowed students to make HIRED a part of their weekly routine.

After attending a few HIRED sessions it is easy for students to see the benefits of attending. It is evident that students are seeing the benefits because they are returning every week. A student's time is very limited and they will spend it very conservatively. Students of all years and disciplines attend HIRED sessions on a weekly basis. HIRED sessions expose even senior students to new opportunities by displaying the diverse opportunities within the featured companies. For example, a company that is known for its civil engineering will still have mechanical, biosystems, electrical and computer engineering students in the room. With direct interaction with industry representatives, students are able to ask questions, learn, and become comfortable with engaging with professional engineers about various topics such as: opportunities in the industry, technological advancements, and workforce preparation. Committing one hour on a weekly basis students can develop and refine their abilities to interact with, and learn from engineers working within industry. This isn't a lot of time for the students, especially when they are using that time to eat a meal while they learn. The learning opportunities provided to students by attending HIRED is very much a formative process, becoming a part of their lifelong learning.

\subsection{Logistical Challenges}

The provision of HIRED requires a consistent and coordinated effort by the administration of the Coop/IIP and the UMES. Co-op/IIP facilitates the industry booking and financial sponsorship for the food. This administrative burden is high. The event occurs every Monday through out the fall and winter terms. The industry partners require a consistent point of contact. The required administrative effort and consistency can be a challenge for students. It is exactly this consistent effort that makes HIRED successful.

Some of the special logistics include selecting a time for the event that coincides with the end of the majority of classes and laboratory sections. This allows students to move directly from class to the HIRED event without a waiting period that may cause students to wait for the event to start. A waiting period is often a reason for a student to go home or otherwise leave campus without attending the event. A required time of waiting would negatively impact student participation.

Previous ad hoc attempts to connect students with industry, typically in industry led information sessions, were often affected by a lack of student participation and required a significant administrative effort without a guarantee of success. The start time of HIRED aligned with the end of classes, the administrative support of Co-op/IIP, the promotion from the UMES as well as a faculty effort, initiated by the Dean of Engineering, to not schedule midterms on Monday evenings. This was negotiated with the Executive of the Faculty. Although it is impossible to guarantee there will be no midterm exams on any given Monday night their frequency of occurrence and therefore their negative effect on student participation in the HIRED events has been greatly reduced.

The promotion of this activity was a challenge as the program first began. It is difficult to email students about the events as they are inundated with email from administration, fellow students and life in general. It is difficult to stand each week on a poster and generally poster boards on campus are loosely controlled. In order to gain the attention of students, UMES decided to use a chalk board. This "no tech" solution has proven effective. The chalk board is strategically located in the Engineering and Information Technology Centre so it is viewed as students enter the building and wait in line for coffee. This updating of the chalkboard requires a consistent effort to be sure the information is always current. The UMES have taken this seriously and have created an air of importance for this board that saw a rival student group on campus attempt to kidnap the board and hold it for ransom. This is generally considered an indication of the board's status and importance to the students. Students now anticipate its weekly updating as an important item of note each week.

\section{WIDE RANGE OF BENEFITS}

The introduction of the HIRED program to the Faculty of Engineering at the University of Manitoba has led to the availability of time and space to invite industry to a welcoming audience. Students are anticipating their presentations and are prepared to engage. This changes the dynamic for the conversation from a one-way conversation coming from industry with an unknown level of interest from the audience to an engaged audience asking for specific information. A student's calendar is limited and HIRED has become a 
valuable time for students to learn and get information that is hard to include or is less effectively presented during the majority of technical courses.

\subsection{Graduate Attributes and Employability are Highlighted for Students and Industry}

Many Engineering professional organizations such as the Association of Engineers and Geoscientists of Manitoba, Friends of Engineering Manitoba Inc, Aerospace Engineering Liaison Group, Canadian Manufactures and Exporters of Manitoba and other industry partners in the community had expressed their need to present students with their member companies to share opportunities for employment, information about career development and other information that would benefit students as well as benefiting the companies themselves. Companies are interested in reinforcing the need for students to focus on graduate attributes. Companies will present the attributes as the essential skills for success within a given company or industry sector as well as suggesting extracurricular activities that support and provide opportunities to gain skills and experiences in those areas. They may discuss their own company initiatives for allowing Engineers in Training to further enhance those skills within their own companies.

For example, at a HIRED event an Engineering manager from the Manitoba Health Care Innovation Centre explained to students that they must become comfortable with making presentations. He explained that that a large portion of his everyday work consists of preparing for and giving presentations. $\mathrm{He}$ encouraged students to seek opportunities to make presentations. It requires a lot of practice to prepare and delivery presentations and he concluded that both are important skills to further an engineering career. These skills are represented in the graduate attributes A7 (written, visual and oral communications). Other presentations emphasizing the graduate attributes have included the following attributes; specific technical innovations occurring in industry (A knowledgebase for engineering attribute A1, Design for engineering attribute A4), workplace health and safety case studies presented and discussed (Impact of engineering on society/environment for A9, Ethics and equity for attribute A10), Appropriate behavior in the workplace (professionalism A8) and the review of operational excellence and continuous improvement (Problem analysis A2 and Investigation A3).

\subsection{Students Gain Industry Awareness}

For many engineering students the pursuit for employment initiates the need to better understand the job market and potential employers. Often when a student first inquires about summer opportunities they only hear about opportunities at well-known companies in Winnipeg including Manitoba Hydro, Boeing, and MacDon Industries. What students often don't realize is that there are many more opportunities outside of these easy to find, highly pursued companies. It is important that students know about the many opportunities, but more vital what qualifications are required by employers for a work term.

Searching for opportunities online can be very difficult and often leads students to find companies that are already known to them. Many companies do not update their websites regularly and do not properly advertise their various employment opportunities. Often job postings don't include what time of the year to apply or required qualifications. Connecting with industry on a weekly basis enables students to continuously develop a knowledge of the activities of various companies, learn what qualifications are sought after, and when to apply.

One of the biggest struggles students have in finding jobs is knowing what skills, knowledge, and experience they need in order to be ready for industry. For today's students, passing classes isn't enough on your resume to find a summer work term; employers want students that have ready to apply skills and hand on experience. HIRED directly provides students an employer's perspective on how to effectively develop in addition to the classroom. Frequently discussion includes: what technologies are important to know, how course work translates to skills in the workforce, and the importance of soft skills. Additionally students seek advice on the smaller things such as: what stands out on a resume, who to address in a cover letter, or how to dress for an interview. Ultimately students learn that there is no exact formula to landing any job, but what skills they need to be developing in order to stand out when on the hunt for employment.

\subsection{Industry Support}

The HIRED events provide a ready-made opportunity for industry to connect with students. There is no administrative burden to plan the event. Industry need only pay for the foods and arrive prepared to make a short presentation. In the past an industry partner may have spent months planning an event at their own time and expense. These events were difficult to plan on campus and the results could not be anticipated. HIRED events are consistently attended with students ready to engage. Industry have now

CEEA15; Paper 033

Hamilton, ON; May31-June 3, 2015 
begun to count on the availability of a HIRED event to promote their company or industry. It is now the normal.

\subsection{Benefits for Student Groups}

The co-curricular activities serve to support the goals of HIRED. It is imperative that these groups make contact with and forge relationships with industry. HIRED events bring industry with the desire to meet and connect with students on campus. HIRED provides an opportunity for the student groups to meet new sponsors and mentors. As a result students groups have included attendance at HIRED as a recommended and sometimes mandatory activity for their membership. The reach of the HIRED events is beyond what student groups typically connect with and the ongoing administration and logistics of the HIRED program would not be reasonable for students to maintain in the long term. It has been key for the faculty to partner with students and industry to provide these opportunities.

\subsection{Students Continue to Make Further Connections}

Student response to the HIRED experience has been to pursue even more contact with industry. The technical societies have initiated a Thursday night opportunity called "Ask Me Anything” (AMA). These events are not in competition with the HIRED event but are intended compliment it. The AMA is run in a similar manner although with less frequency to allow students to finish classes and have some food as they meet new contacts from industry. AMA's tend to focus on an industry sector instead of an individual company and are based on question and answer instead of a presentation. Often recent alumni will be included on the industry panel and students can inquire directly about how their current education is applied at work.

The response from students both individual and in their co-curricular groups and technical societies has been with out exception, to promote, attend and collaborate to expand the HIRED initiative. The initiative was noted by an external review of the faculty's Co-operative Education and Industrial Internship Program (Co-op/IIP) as the "now famous" Monday night HIRED.

\section{Results}

\subsection{The numbers}

The HIRED Program has just completed its second successful year, with 22 events completed in the
2014/2015 academic year. There were 13 employer information sessions, 6 student groups and professional development workshops and 3 industry sector council presentations. All of these sessions were extremely well attended with participation numbers ranging from between 60-130 students. There are plans to be more strategic in organizing these events in the upcoming year to ensure the needs of the students are being met and that the program is not just responding to the needs of employers. Future events could include: grouping small and medium size companies in panel discussions, workshops with employers using Six Sigma principles in their operations, and speed networking to help students prepare and practice their networking skills.

\subsection{Student Response}

The response to HIRED has been positive. Students have realized that they need and enjoy the regular interaction with industry. It has become part of the student experience and is introduced to students at orientation. There is an assumption that students should plan to attend HIRED events that will occur every Monday night. Students appreciate the industry professionals who present at HIRED for taking the time to share about the innovations and changes in their companies and industries. The personal stories of these professionals inform and inspire students to connect with industry as often as possible. The students of the faculty as a whole have become more aware of the diversity of the profession and the essential skills required to be successful as a Profession Engineer.

\section{Conclusion}

HIRED events have helped students, student groups, faculty, industry, and engineering community to make important connections and develop a meaningful platform to share, learn and grow with each other. With limited resources, the faculty has created a program that it easily managed, marketed, and extremely successful in meeting its goals and addressing the needs of industry and students. HIRED has already started confirming employers for next year and the program will continue to build on our past success. HIRED is now considered an integral part of the programming in the Faculty of Engineering at the University of Manitoba. 


\section{Acknowledgements}

We would like to acknowledge Dr. Douglas Ruth, NSERC Design Chair, at University of Manitoba for financial support of this initiative. We would like to thank Amber Skarbeck, Executive Director, Friends of Engineering Manitoba Inc., and the UMES, for their partnership on this project.

\section{References}

Canada, Parliament, Report of the Standing Committee on Human Resources, Skills and Social Development (2012, December). Labour and Skills Shortages in Canada: Addressing Current and Future Challenges. Retrieved April 14, 2015, from http://www.parl.gc.ca/content/hoc/Committee/ 411/HUMA/Reports/RP5937523/humarp09/h umarp09

CBI (2009). Future Fit- Preparing graduates for the world of work. Retrieved August 14, 2015, from

http://www.cbi.org.uk/media/1121435/cbi_uu k_future_fit.pdf

Civian, J. (2007). Critical Talent and the New Career Paradigm: Some Industry Insights. Retrieved April 14, 2015 from http://www.abcdependentcare.com/docs/curre nt_news.shtml

Cole, L. (2015, April 14). Developing Strong Partnerships with Employers [Personal interview].
Education Advisory Board (2013). Developing Next Generation Career Services- Strategies for Increasing Alumni and Employer Engagement. Retrieved April 14, 2015, from http://www.eab.com/research-andinsights/student-affairsforum/studies/2012/developing-nextgeneration-career-services

Province of Manitoba, Labour Market Information (2014). Manitoba Occupational Forecast 2014-2020. Retrieved April 14, 2015, from http://www.gov.mb.ca/tce/lmi/pdf/labour_mar ket_occup_report.pdf

Royal Bank of Canada, RBC Economics (2014). Questions and Answers on the State of SMEs in Canada. Retrieved April 14, 2015, from http://www.rbc.com/economics/economicreports/pdf/other-reports/QA_SMEs.pdf

Tabor, D. (2015, April 14). Developing Strong Partnerships with Employers (Personal interview).

Workopolis Research (2014), Thinkopolis VI: Moving Work | Year in Review. Retrieved April 14, 2015 from http://works.workopolis.com/research/2014/ december/Thinkopolis\%20VI\%20$\% 20$ Moving\%20Work\%20 